\title{
PERBANDINGAN SOSIAL EKONOMI PEDAGANG KAKI LIMA SEBELUM DAN SESUDAH PEMBANGUNAN TAMAN KOTA DI KOTA PARIAMAN
}

\author{
Reni Faula Agusni \\ Program Studi Pendidikan Geografi STKIP PGRI Sumatera Barat \\ agusnirenifaula@gmail.com
}

\begin{abstract}
This research aims to describe a situation as it is and describe it with the variables, studied. Comparative Social economic Street Vendor Before andafter Construction of Park City in Kota Pariaman. This type of research is classified in descriptive. The population in this research traders who are around Park City. Retrieval technique used is total sampling the entire community activities which amount to 45 people. Data were collected using aangket and analyzed by descriptive analysis technique using a percentage formula. The results found that: 1) The business unit that develops in Park City consists of 45 units, generally in the form of food and beverages business. Prior to the State Parks in general respondents had put the same effort and was carried out in their respective places, and there are only very few respondents who did not have any previous attempt. There were changes in the level of income before and after construction of city parks, the relative increase its income, public revenue ranged between Rp.750.000-Rp.1.350.000, sometimes extra income, the amount of additional income ranging from 500,000, revenues meet daily needs enough, a family needs for children's education expenses, dependents in the family of one man, who took the child to add revenue, expenditure average basic monthly> Rp.1.350.000,2) There were changes in the type of interaction and language before and after construction of individual interaction with the city park good individual, individual interactions with individual language Indonesian and Regional Languages, the interaction of individuals with a good group, a language group interaction of individuals with Indonesian and Regional Languages, group interaction with either group, a language group interaction with a group of Indonesian and English Daerah.3) There were changes in the level of employment of family members of one person, not a family member of one person.
\end{abstract}

Keyword: Comparative Social economic, level of income, level of interaction, level of education

Abstrak

Penelitian ini bertujuan untuk menggambarkan suatu keadaan sebagaimana adanya dan mendiskripsikannya dengan variabel-variabel, yang diteliti. Perbandingan Sosial Ekonomi Pedagang Kaki Lima Sebelum Dan Sesudah Pembangunan Taman Kota Di Kota Pariaman

Jenis penelitian ini tergolong pada deskriptif. Populasi dalam penelitian ini adalah pedagang yang ada di sekitar Taman Kota. Teknik pengambilan yang digunakan adalah total sampling yaitu seluruh masyarakat yang beraktifitas yang berjumlah 45 orang. Pengambilan data dilakukan dengan menggunakan angket kemudian dianalisis dengan teknik analisis deskriptif menggunakan formula persentase. Hasil penelitian menemukan : 1) Unit usaha yang berkembang di Taman Kota terdiri dari 45 unit, pada umumnya berupa usaha makan dan minuman. Sebelum adanya Taman Kota pada umumnya responden sudah melakukan usaha yang sama dan itu dilakukan di tempatnya masing-masing, dan hanya terdapat sangat sedikit responden yang tidak punya usaha sebelumnya. Terjadi perubahan tingkat pendapatan sebelum dan sesudah pembangunan taman kota, pendapatanya relatif meningkat, pendapatan masyarakat berkisar antara Rp.750.000Rp.1.350.000, penghasilan tambahan kadang-kadang, jumlah penghasilan tambahan berkisar Rp.500.000, pendapatan memenuhi kebutuhan sehari-hari cukup, kebutuhan keluarga untuk biaya pendidikan anak, tanggungan dalam keluarga 1 orang,yang ikut menambahkan pendapatan anak, pengeluaran pokok rata-rata perbulan >Rp.1.350.000,2) Terjadi perubahan jenis interaksi dan bahasa sebelum dan sesudah pembangunan taman kota interaksi individu dengan individu baik, bahasa interaksi individu dengan individu Bahasa Indonesia dan Bahasa Daerah, interaksi individu dengan kelompok baik, bahasa interaksi individu dengan kelompok Bahasa Indonesia dan 
Bahasa Daerah, interaksi kelompok dengan kelompok baik, bahasa interaksi kelompok dengan kelompok Bahasa Indonesia dan Bahasa Daerah.3) Terjadi perubahan tingkat tenaga kerja dari anggota keluarga 1 orang, dari bukan anggota keluarga 1 orang.

\section{PENDAHULUAN}

Dalam kehidupan terdapat suatu unsur yang saling menguntungkan antara satu elemen dengan elemen yang lainnya. Sebuah kehidupan di perkotaan dapat digambarkan secara sederhana yang terdiri dari manusia, hewan, tumbuhan, sungai dan areal terbuka lainya. Bertambahnya jumlah penduduk maka bertambah pula kebutuhan lahan yang digunakan. Pembangunan yang dilakukan untuk pemenuhan kebutuhan hidup, sering tidak seimbang dengan usaha yang dilakukan, contohnya saja pembangunan pusat pertokoan, pembangunan permukiman serta keberadaan pusat industry yang tidak memperhatikan suatu daerah untuk dijadikan Taman Kota. Pembangunan adalah proses perubahan yang direncanakan untuk memperbaiki berbagai aspek kehidupan masyarakat.

Pembangunan pada umumnya bersifat multisektoral dalam arti pertama sebagai metode pembangunan masyarakat sebagai subjek pembangunan kedua sebagai program dan ketiga sebagai gerakan masyarakat dalam melaksanakan pembangunan dilandasi oleh kesadaran untuk meningkatkan kehidupan yang lebih baik (Setyono, 2002;34).

Menurut Undang-Undang No 26 Tahun 2007 tentang Penataan Ruangdan peraturan menteri PU No.05/PRT/M/2008 tentang Pedoman Penyediaan dan Pemanfaatan Ruang Terbuka Hijau (RTH) adalah area memanjang/jalur dan atau mengelompok, yang penggunaanya lebih bersifat terbuka, tempat tumbuh tanaman, baik yang tumbuh tanaman secara alamiah maupun yang disengaja.

Ruang terbuka hijau juga di pahami sebagai ruang yang di peruntukan sebuah ruang kota yang dapat diakses secara umum dan Cuma-Cuma oleh masyarakat kota dari berbagai lapisan, ruang terbuka adalah ruang yang berfungsi dan manfaatnya di gunakan sepenuhnya untuk kepentingan publik atau masyarakat luar dan bukan untuk seseorang ataupun kelompok-kelompok tertentu (Hastijanti, 2006:32).

RTH memiliki fungsi utama (intrinsik) yaitu fungsi ekologis, dan fungsi tambahan (ekstrinsik) yaitu fungsi arsitektural, sosial dan fungsi ekonomi. Fungsi 
ekologis RTH yaitu dapat meningkatkan kualitas air tanah, mencegah banjir, mengurangi polusi udara dan mengatur iklim mikro. Fungsi RTH secara ekonomi adalah meningkatkan pendapatan masyarakat dan meningkatkan jumlah wisatawan yang berkunjung. Dengan meningkatnya jumlah wisatawan maka pendapatan masyarakat juga meningkat. Keberadaan Taman Kota atau Ruang Terbuka Hijau, sangatlah penting bagi kehidupan kita. Selain fungsinya sebagai tempat rekreasi dan untuk bersantai. Ternyata keberadaan Taman Kota juga berfungsi sebagai penghijauan dan memperindah tata ruang Kota serta dapat mengurangi dampak polusi yang ditimbulkan dari cerobong-cerobong kendaraan.

Kebutuhan warga kota terhadap taman kota sama pentingnya dengan kebutuhan sandang dan pangan, karena keberadaanya bisa memberikan nilai positif terhadap produktifitas warga dalam berkegiatan sehari-hari. Dalam hal ini di perlukan kerja sama yang baik dan bersinergi antara pemerintah dengan masyarakat sehingga pembangunan yang di harapkan dapat terlaksana. Pada pembangunan prasarana, kebijakan di arahkan pada pembangunan dan peningkatan infrastruktur pemerintah ekonomi dan pelayanan pubik dengan tujuan untuk mendukung pengembangan wilayah, terutama wilayah yang belum tersentuh pembangunan pusat-pusat pemerintah, kawasan pengembangan ekonomi rakyat.

Berdasarkan observasi awal pada tanggal 14 Oktober 2015 Sebuah lapangan yang berada di Kota Pariaman dulu fungsinya minim sekarang sangat meluas yaitu sebagai taman kota. Lapangan merdeka Kota Pariaman terletak di pusat kota juga bertatapan langsung dengan SMP Negeri 1 Pariaman. Keberadaanyapun dimanfaatkan para pelajar ini untuk belajar olah raga di sana. Seiring dengan berjalannya waktu lapangan ini pun semakin diperbaharui. Hingga lapangan ini menjadi multiguna. Dulu lapangan ini digunakan untuk shalat id dan adanya sekelompok anak karate latihan disana. Namun sekarang tidak dapat lagi kita temukan disana. Lapangan itu sudah disulap menjadi taman yang indah yang memiliki pesona tersendiri. Ada bundaran bulat di tengahnya dengan air mancur disana. Juga ada toilet bawah tanah. Dan pastinya banyak tempat sampah demi 
menjaga kebersihan lingkungan bersama. Taman ini baru selesai akhir Desember 2010 .

Taman Kota adalah paru-paru sebuah kota dan juga bisa dijadikan sebagai tempat wisatawan yang ingin datang ke Kota Pariaman. Dan seiring berjalanya waktu di duga Bahwa sebelumnya dilihat dari pendapatan masyarakat hanya berjualan di depan rumahnya dan penghasilan yang mereka dapatkan kurang, jadi semakin kurang atau rendahnya pendapatan masyarakat maka semakin kurang bagus tingkat kehidupan seseorang tersebut. Lalu dari segi Interaksi sosial Masyarakat yang hanya berjualan di depan rumah interaksinya kurang, interaksinya biasa saja karena si pembeli hanya di sekitar rumah. Dan begitu juga dari Penyerapan tenaga kerja Masyarakatnya berjualan yang hanya di depan rumah tidak memerlukan tenaga kerja dan juga tidak mencari tenaga kerja lain, karena dari tenaga kerja keluarga sendiri sudah memenuhi permintaan pengunjung. Adanya pembangunan Taman Kota dianggap sebagai peluang bagi masyarakat Kota Pariaman untuk berjualan. Semakin hari semakin banyakpedagang yang berjualan disekitar Taman Kota, ada yang awalnya hanya berjualan di depan rumah dan ada pula yang baru mulai berjualan. Untuk itu perlu diadakan penelitian mengenai keberadaan Taman Kota kaitanya dengan pendapatan masyarakat, interaksi sosial, dan penyerapan tenaga kerja. Berdasarkan latar belakang diatas maka penulis tertarik melakukan penelitian mengenai "Perbandingan Sosial Ekonomi Pedagang Kaki Lima Sebelum Dan Sesudah Pembangunan Taman Kota Di Kota Pariaman”.

\section{METODOLOGI}

Jenis penelitian ini tergolong pada penelitian deskriptif, penelitian deskriptif menggunakan dan menginterprestasi apa adanya (Arikunto, 2000) mengatakan penelitian deskriptif adalah penelitian dengan menjelaskan atau menggambarkan variabel. Populasi menurut Arikunto (2006;130) adalah keseluruhan objek penelitian, apabila seseorang ingin meneliti semua wilayah yang ada dalam penelitian maka akan menjadi penelitian populasi. Adapun populasi dalam penelitian ini adalah semua masyarakat yang berjualan di sekitar taman kota pariaman yang berjumlah 45 orang pedagang. Adapun pengambilan sampel pada 
penelitian ini untuk melihat pembangunan taman kota bagi sosial ekonomi masyarakat kota pariaman, dimana sebelum adanya taman tidak ada yang berjualan di dekat taman kota.

Instrumen adalah suatu alat pengumpulan data, instrumen ini dikembangkan dengan bantuan kajian teori, variabel, sub variabel dan selanjutnya dikembangkan dalam bentuk indikator-indikator dan dapat di terapkan dalam butir-butir pertanyaan. Adapun bentuk instrumen pengumpulan data primer adalah dengan menggunakan angket. Sesuai dengan jenis data kajian penelitian yang hendak di capai maka data yang katagorikan adalah data primer dan data sekunder. Data primer yaitu data yang berhubungan dengan kesesuaian tata ruang taman kota.Sedangkan data sekunder adalah keadaan geografis atau data yang mendukung dan menunjang dalam penelitian.Sesuai dengan jenis data yang di ambil dalam penelitian ini, maka sumber data sekundernya di peroleh dari kantor lurah dan instansi

di anggap mempunyai data yang releven, sedangkan data primernya adalah responden di lapangan.Data primer di peroleh melalui penyebaran angket dengan sampel responden yaitu daftar pertanyaan dan sekunder di peroleh melalui observasi, pencatatan dari wawancara dengan pejabat setempat seperti, kantor lurah.Sesuai dengan rumusan masalah, tujuan penelitian, jenis data, sumber data, dan alat pengumpulan data.

\section{PEMBAHASAN}

Pada pembahasan ini akan dibahas hasil penelitian tentang perbandingan sosial ekonomi pedagang kaki lima sebelum dan sesudah pembangunan taman kota di kota pariaman yang meliputi: 1) Bagaimana pendapatan masyarakat sebelum dan sesudah pembangunan Taman Kota Di Kota Pariaman. 2) Bagaimana interaksi masyarakat sebelum dan sesudah pembangunan Taman Kota Di Kota Pariaman. 3) Bagaimana penyerapan tenaga kerja masyarakat sebelum dan sesudah pembangunan Taman Kota Di Kota Pariaman.

Pertama, tingkat pendapatan masyarakat sebelum dan sesudah pembangunan Taman Kota Di Kota Pariaman dari 45 responden adalah 10 responden $(22,4 \%)$ selalu meningkat, 22 responden $(48,8 \%)$ meningkat, 9 
responden $(22,4 \%)$ selalu meningkat, 22 responden $(48,8 \%)$ meningkat, 9 responden $(20 \%)$ tetap, 4 responden $(8,8 \%)$ menurun. Sesudah pembangunan taman kota dari 45 responden adalah 21 responden (46,6\%) selalu meningkat, 15 responden $(33,5 \%)$ meningkat, 7 responden $(15,5 \%)$ tetap, 4 responden $(4,4 \%)$ menurun. Jadi dapat disimpulkan bahwa pendapatan masyarakat sebelum dan sesudah pembangunan taman kota terjadi perubahan, dilihat dari 45 responden persentase tertinggi adalah meningkat $(48,8 \%)$ dan selalu meningkat $(46,6 \%)$.

Berdasarkan pembahasan di atas sesuai dengan teori yang dikemukakan oleh Sherraden dalam Depi Rinaldo (2013). Pendapatan adalah gambaran yang lebih tepat tentang posisi ekonomi keluarga yang merupakan jumlah keseluruhan pendapatan atau kekayaan keluarga termasuk semua barang, hewan peliharaan, pakaian dan membagi pendapatan menjadi tiga kelompok yaitu pendapatan tinggi, pendapatan sedang dan pendapatan rendah, dinyatakan bahwa pendapatan seseorang diartikan sebagai jumlah uang atau barang yang diterima sebagai hasil kerja yang dilakukan,

Kedua, Tingkat interaksi masyarakat sebelum dan sesudah pembangunan Taman Kota Di Kota Pariaman, dari 45 responden adalah 18 responden (40\%) sangat baik, 18 responden (40\%) baik, 9 responden (20\%) kurang baik, 0 responden $(0 \%)$ biasa saja. Sesudah pembangunan taman kota dari 45 responden adalah 16 responden $(35,5 \%)$ sangat baik, 17 responden $(37,7 \%)$ baik, 7 responden $(15,6 \%)$ kurang baik, 5 responden $(11,2 \%)$ biasa saja. Jadi dapat disimpulkan bahwa pendapatan masyarakat sebelum dan sesudah pembangunan taman kota terjadi perubahan, dilihat dari 45 responden persentase tertinggi adalah sangat baik (40\%) dan baik $(37,7 \%)$.

Sesuai dengan pernyataan Interaksi sosial adalah hubungan timbal balik antara individu dengan individu, individu dengan kelompok dan kelompok dengan kelompok dari satu tempat ke tempat yang lain(Haryanto dan Nugrohadi, 2011).

Ketiga, Bagaimana penyerapan tenaga kerja masyarakat sebelum dan sesudah pembangunan Taman Kota Di Kota Pariaman, dari 45 responden adalah 23 responden $(51,1 \%) 1$ Orang, 0 responden $(0 \%) 2$ Orang, 5 responden $(11,2 \%)$ lebih dari 3 orang, 17 reponden $(37,7 \%)$ tidak ada. Sesudah pembangunan taman 
kota dari 45 responden adalah 21 responden $(46,6 \%) 1$ Orang, 4 responden $(8,9 \%)$ 2 Orang, 4 responden $(8,9 \%)$ lebih dari 3 orang, 16 responden $(35,6)$ tidak ada. Jadi dapat disimpulkan bahwa pendapatan masyarakat sebelum dan sesudah pembangunan taman kota terjadi perubahan, dilihat dari 45 responden persentase tertinggi adalah 1 orang $(51,1 \%)$ dan tidak ada $(35,6 \%)$.

Berdasarkan pembahasan di atas sesuai dengan teori yang dikemukakan oleh (idris dan yanuarti, 2007). Tenaga kerja adalah dalam usia kerja atau jumlah seluruh penduduk dalam suatu negara yang dapat memproduksi barang dan jasa jika ada permintaan terhadap tenaga kerja mau berpartisipasi dalam aktivitas tersebut.

\section{KESIMPULAN}

Hasil penelitian terhadap perubahan sosial ekonomi pedagang kaki lima sebelum dan sesudah pembangunan Taman Kota dikota Pariaman masyarakat sebelum dan sesudah pembangunan Taman Kota :

1. Pendapatan masyarakat sebelum dan sesudah pembangunan Taman Kota Di Kota Pariaman dilihat dari hasil penelitian terjadi perubahan dari 45 responden pada umumnya meningkat sebelum pembangunan taman kota $(48,8 \%)$ dan selalu meningkat sesudah pembangunan taman kota $(22,4 \%)$.

2. Interaksi masyarakat sebelum dan sesudah pembangunan Taman Kota Di Kota Pariaman.dilihat dari hasil penelitian terjadi perubahan dari 45 responden pada umumnya baik sebelum pembangunan taman kota $40 \%$ dan baik sesudah pembangunan taman kota $37,7 \%$.

3. Penyerapan tenaga kerja masyarakat sebelum dan sesudah pembangunan Taman Kota Di Kota Pariaman dilihat dari hasil penelitian terjadi perubahan sebelum pembangunan taman kota $51,1 \%$ dan sesudah pembangunan taman kota $46,6 \%$.

\section{DAFTAR PUSTAKA}

Anonim, 2009. Pelatihan produksi Bio-Ethonol. Bogor. Gusmailina.

Arikunto, suharsimi. 2006. prosedur penelitian. Jakarta : Rineka Cipta 
. 2002. Prosedur penelitian suatu pendekatan praktek. Jakarta : Rineka Cipta

Deddy \& Riyadi. 2005. Pengertian pembangunan w.w.w.google.com

Haryanto \& Nugrohadi. 2011. Pengantar sosiologi dasar. Jakarta: PT Prestasi Pustaka raya

Idris \& Ramel Yanuarti.2007. Ekonomi ketenagakerjaan. UNP Press UNP

Kasmir.2006. Kewirausahaan. jakarta: Raja Grafindo Persada

Noveria Mita. Et al. 2011. Pertumbuhan penduduk dan kesejahteraan. LIPI Press, Anggota IKAPI. Jakarta

Purnomohadi, Ning. 2006. Ruang Terbuka Hijau sebagai unsur utama tata. Jakarta: Direktoratjendral penata ryang kementrian pekerjaan umum

Retno,hastijanti. 2006. Ruang publik untuk siapa. Tersedia di http://www. Untag Sby.ac.id/index.php?mod= berita $\& \mathrm{id}=49$ diakses 2 februari

Salim, abbas. 2002. Manajemen Transportasi. Jakarta: PT. RajaGrafindoPersada Setyono.2002. Pengertian Pembangunan w.w.w.google.com

Sherraden, michael. 2006. Aset untuk orang miskin. Jakarta: Raja Grafindo 